\title{
The use of aerial and close-range photogrammetry in the study of dinosaur tracksites: Lower Cretaceous (upper Aptian/lower Albian) Molfetta ichnosite (Apulia, southern Italy)
}

\author{
Fabio Massimo Petti, Marco Petruzzelli, Jacopo Conti, Luigi Spalluto, \\ Alexander Wagensommer, Massimiliano Lamendola, Roberto Francioso, \\ Giovanni Montrone, Luisa Sabato, and Marcello Tropeano
}

\begin{abstract}
Accurate mapping and three-dimensional models are crucial for studying dinosaur tracks and tracksites at different scales. The use of small Unmanned Aerial Vehicles (UAVs) for mapping and three-dimensional modelling is becoming increasingly common, allowing the capture of high-resolution images comparable to those obtained by terrestrial laser scanners and manned aerial photogrammetry, but with reduced working costs and rapid execution times. The Lower Cretaceous (upper Aptian/lower Albian) Molfetta dinosaur tracksite (Apulia, southern Italy), was used as a test area to evaluate the results of UAV based photogrammetry. We used two different drones having different technical features and for which we set different flight parameters. Ground-based photogrammetry on single footprints was also performed, in the light of the recent introduction of high-resolution digital cameras and powerful processing software, with the aim to evaluate its impact on ichnological, ichnotaxonomical, and ichnosystematic analyses. The accuracy of three-dimensional models, digital elevation models, and orthophotos generated by UAV images is extremely high and allows for rapid mapping and description of vast and/or hardly accessible tracksites with higher accuracy than that obtained from traditional field data or from digital airphotos. By coupling ground- and aerial-based photogrammetry, ichnologists can rapidly obtain consistent and affordable digital models useful to study dinosaur tracksites both at the meso(track) and macroscale (ichnosite). The adoption of aerial and close-range photogrammetry will allow for the rapid production of data with sustainable costs that can be used both by specialists and as a means of conservation and dissemination of knowledge to the public.
\end{abstract}

Petti, Fabio Massimo, Petruzzelli, Marco, Conti, Jacopo, Spalluto, Luigi, Wagensommer, Alexander, Lamendola, Massimiliano, Francioso, Roberto, Montrone, Giovanni, Sabato, Luisa, and Tropeano, Marcello. 2018. The use of aerial and close-range photogrammetry in the study of dinosaur tracksites: Lower Cretaceous (upper Aptian/lower Albian) Molfetta ichnosite (Apulia, southern Italy). Palaeontologia Electronica 21.3.3T 1-18. https://doi.org/10.26879/845 palaeo-electronica.org/content/2018/2317-uavs-and-dinosaur-tracksites 
Fabio Massimo Petti. MUSE - Museo delle Scienze di Trento, Corso del Lavoro e della Scienza 3, 38122 Trento, Italy; fabio.petti@muse.it and PaleoFactory, Dipartimento di Scienze della Terra, Sapienza Università di Roma, Piazzale Aldo Moro, 5, I-00185 Rome, Italy Marco Petruzzelli. Dipartimento di Scienze della Terra e Geoambientali, Università degli Studi di Bari Aldo Moro, Via Orabona, 4 - 70125 Bari, Italy. marco.petruzzelli@uniba.it Jacopo Conti. PaleoFactory, Dipartimento di Scienze della Terra, Sapienza Università di Roma, Piazzale Aldo Moro, 5, I-00185 Rome, Italy and Dipartimento di Scienze della Terra, Sapienza Università di Roma, Piazzale Aldo Moro, 5, I-00185 Rome, Italy. jacopo.conti@uniroma1.it

Luigi Spalluto. Dipartimento di Scienze della Terra e Geoambientali, Università degli Studi di Bari Aldo Moro, Via Orabona, 4 - 70125 Bari, Italy, and Autorità di Bacino Della Puglia - Distretto dell'Appennino Meridionale c/o INNOVAPUGLIA (Ex Tecnopolis CSATA) Str. Prov. per Casamassima, Km 3-70010 Valenzano (Bari), Italy. luigi.spalluto@adb.puglia.it

Alexander Wagensommer. GRID (Gruppo di Ricerca sulle Impronte di Dinosauro), San Giovanni Rotondo, Foggia, Italy. wagensommer@tiscali.it

Massimiliano Lamendola. Autorità di Bacino Della Puglia - Distretto dell'Appennino Meridionale c/o INNOVAPUGLIA (Ex Tecnopolis CSATA) Str. Prov. per Casamassima, Km 3 - 70010 Valenzano (Bari), Italy. massimiliano.lamendola@adb.puglia.it

Roberto Francioso. Autorità di Bacino Della Puglia - Distretto dell'Appennino Meridionale c/o INNOVAPUGLIA (Ex Tecnopolis CSATA) Str. Prov. per Casamassima, Km 3 - 70010 Valenzano (Bari), Italy. roberto.francioso@adb.puglia.it

Giovanni Montrone. Dipartimento di Scienze della Terra e Geoambientali, Università degli Studi di Bari Aldo Moro, Via Orabona, 4 - 70125 Bari, Italy. giovanni.montrone@uniba.it

Luisa Sabato. Dipartimento di Biologia, Università degli Studi di Bari Aldo Moro, Via Orabona, 4 - 70125

Bari, Italy and Dipartimento di Scienze della Terra e Geoambientali, Università degli Studi di Bari Aldo Moro, Via Orabona, 4 - 70125 Bari, Italy. luisa.sabato@uniba.it

Marcello Tropeano. Dipartimento di Scienze della Terra e Geoambientali, Università degli Studi di Bari Aldo Moro, Via Orabona, 4 - 70125 Bari, Italy. marcello.tropeano@uniba.it

Keywords: unmanned aerial vehicles; ichnology; dinosaur footprints; Apulia

Submission: 22 December 2017 Acceptance: 4 September 2018

\section{INTRODUCTION}

Over the last two decades, ichnology, and especially the study of tetrapod fossil footprints, have benefited from the continuous evolution of sensor-based surveying techniques (i.e., triangulation-based laser scanners, terrestrial laser scanners, close-range photogrammetry) and the development of increasingly high-performance systems for the visualization and processing of digital data. These innovative approaches have greatly improved data analysis, both quantitatively and qualitatively, and broadened the horizons of ichnology, increasing the availability and fruition of obtained results. Among these, the most commonly adopted methodology is close-range photogrammetry (Breithaupt and Matthews, 2001; Breithaupt et al., 2001; Matthews and Breithaupt, 2001; Adams and Breithaupt, 2003; Breithaupt et al., 2004; Matthews et al., 2006; Petti et al., 2008a; Adams et al., 2010; Remondino et al., 2010; Falk- ingham, 2012; Matthews and Breithaupt, 2012; Falkingham et al., 2014; Pond et al., 2014; Romilio and Salisbury, 2014; Xing et al., 2015; Lallensack et al., 2015, 2016; Wings et al., 2016; Salisbury et al., 2017), often used in parallel with or as integration of other approaches based on digital technologies, such as total station and GPS surveying equipment and triangulation-based or terrestrial laser scanners (LiDAR $=$ Light Detection and Ranging or Laser Imaging Detection and Ranging; Avanzini et al., 2008; Bates et al., 2008, 2009). Ground-based photogrammetry has been performed both on small- and large-scale items (i.e., single footprints or trackways) and using both close-range and aerial images. The latter were obtained mounting digital cameras on a large variety of aircraft (helicopters, ultralights, single-engine fixed wing aircraft, blimps, and unmanned aircraft systems; Breithaupt et al., 2004; Matthews et al., 2006; Matthews and Breithaupt, 2011a, b, 2012; Chapman et al., 2012; Matthews et al., 2014, 2016; 
Romilio et al., 2017). Although all these approaches provided important results for the study of single tracks, they did not fully satisfy ichnologists, both in terms of resolution or the time of execution and practicality, especially in vast tracksites (see Matthews et al., 2016).

Recently Matthews et al. (2016) and Romilio et al. (2017) reviewed the different approaches used to date, highlighting strong and weak points of each method. In the last two years, Unmanned Aerial Vehicles (UAVs) (i.e., drones: quad-, hexa-, octocopters) have opened a new frontier in threedimensional (3D) ichnology and have been used for the digital modelling of medium-scale outcrops characterized by difficult accessibility (Citton et al., 2017; Romilio et al., 2017), and to digitally preserve and communicate ichnological data (Cipriani et al., 2016).

Different types of UAVs (quadcopter and hexacopter) have been used for $3 \mathrm{D}$ reconstructions of archaeological sites, mainly at the scale of a single site or excavation, and have proved to be able to excellently replace conventional topographic surveys (Field et al., 2017; Nikolakopoulos et al., 2017).

The use of small, remotely controlled UAV platforms in the field of geomatics is becoming increasingly widespread since it allows both highand low-altitude aerial surveys (see Pajares, 2015 for an overview on applications based on UAVs). The rapid diffusion of these methodologies is linked to their rapidity of execution (flight durations from 5-30 minutes), the possibility of surveying areas with difficult access and obtaining images with extremely high resolution, higher than those achieved with the traditional aerial photogrammetry (i.e., helicopters balloon-launched gliders, airships, or balloon). In addition, costs are limited, and drones can be equipped with a wide range of sensors such as video cameras, thermal infrared video sensors, LiDAR, multispectral and hyperspectral sensors, chemical sensors, or even multisensor technologies (Pajares, 2015).

In this study, we performed the 3D mapping of a large and complex dinosaur track-bearing surface (late Aptian/early Albian, Early Cretaceous) in the Molfetta area (geosite of San Leonardo quarry, Apulia, southern Italy; Fiore et al., 2010; Mastronuzzi et al., 2015) by means of ground- and aerialbased photogrammetry (i.e., UAVs: quad-, hexacopters), with the aim of assessing the impact of these two technologies on the documentation and study of small- and large-scale ichnosites, respectively. Moreover, the contribution of these tech- niques to the strategy of study, conservation, management and valorization of the ichnological heritages is discussed.

\section{STUDY AREA}

Several dinosaur track-bearing levels have been discovered to date within the Mesozoic shallow marine deposits of the Apulia Carbonate Platform (Nicosia et al., 2000a, 2000b; Conti et al., 2005; Petti et al., 2008b, 2010; Sacchi et al., 2009; lannone et al., 2012). They span from the Late Jurassic (?late Tithonian) to Late Cretaceous (early Santonian). The herein discussed track-bearing horizon is located in a disused quarry (San Leonardo) close to the town of Molfetta (Lat: 41,18125 $\mathrm{N}$; Long: 16,57287 E; Apulia, southern Italy; Figure 1). Due to the occurrence of well-preserved dinosaur footprints, this site was recently included in the geosite census of the Apulia Region (CGP0137 in Mastronuzzi et al., 2015; see also: www.geositipuglia.eu). The trampled surface is exceptionally well exposed at the top of a 15-m thick carbonate succession, belonging to the Calcare di Bari Formation and has been dated to the late Aptian/early Albian based on oligotrophic benthic foram assemblage (Fanti et al., 2014; Petruzzelli, 2017). Preliminary analyses performed at this site provided a wealth of information gained with the integration of close-range photogrammetry, LiDAR, and GPS surveying equipment (Petruzzelli et al., 2016).

The studied surface covers an area of about $2700 \mathrm{~m}^{2}$ (Figure 2) and yields several tridactyl foot-

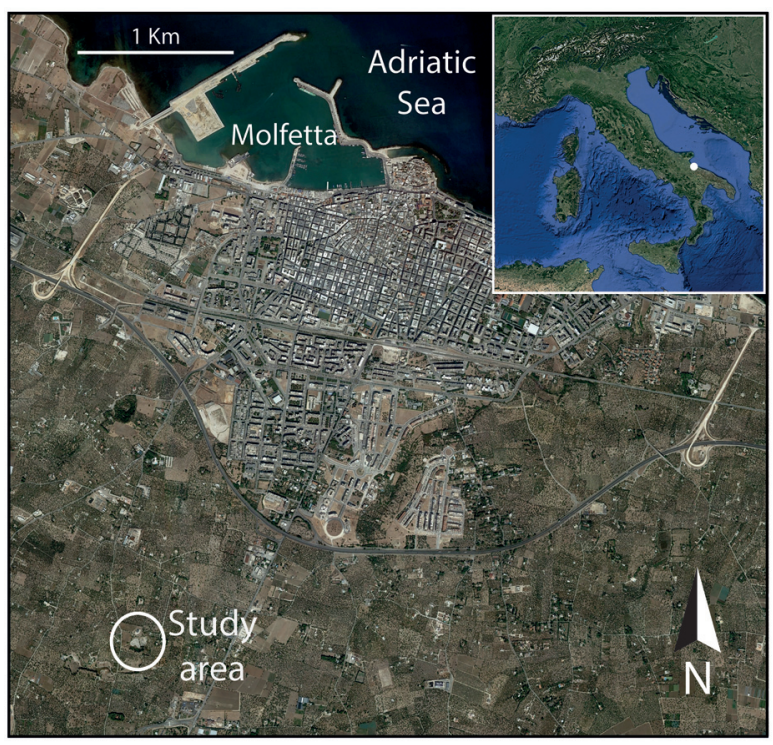

FIGURE 1. Locality map showing the San Leonardo quarry tracksite, Apulia, southern Italy. Image obtained using Google Earth Pro. 


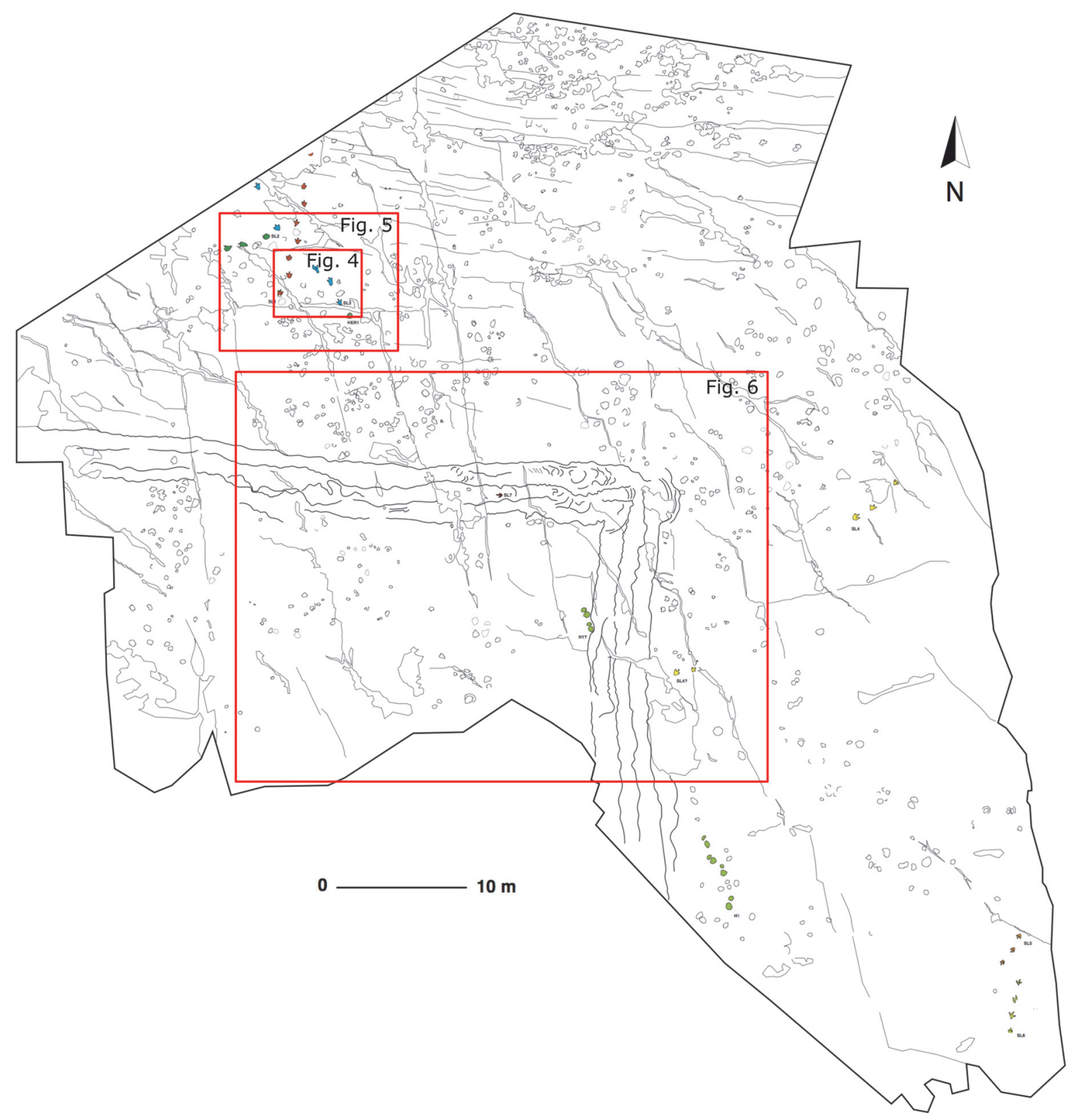

FIGURE 2. Molfetta tracksite - Map of the trampled surface.

prints, produced by medium-sized theropods and mostly arranged in seven different bipedal trackways. Detailed field mapping of the track-bearing surface has revealed two short quadrupedal trackway segments, possibly pertaining to the same trackway, as well as numerous isolated footprints, that indicate the presence of small- to mediumsized herbivorous dinosaurs. Track arrangement suggests they were produced during three to four distinct time intervals. The surface is marked by an enigmatic and meter-sized "L-shaped" trace char- acterized by a medial raised rim and several meniscate structures, possibly made by a sliding tetrapod (?turtle). Tracks were impressed on shallow, subtidal wackestones, lacking clear sedimentological characteristics related to long-lasting subaerial exposure. The occurrence of dinosaur tracks is, therefore, the best evidence for occasional and brief periods of exposure, that did not allow the development of sedimentary structures such as desiccation cracks (Petruzzelli, 2017). The trampled surface is covered by shallow subtidal 


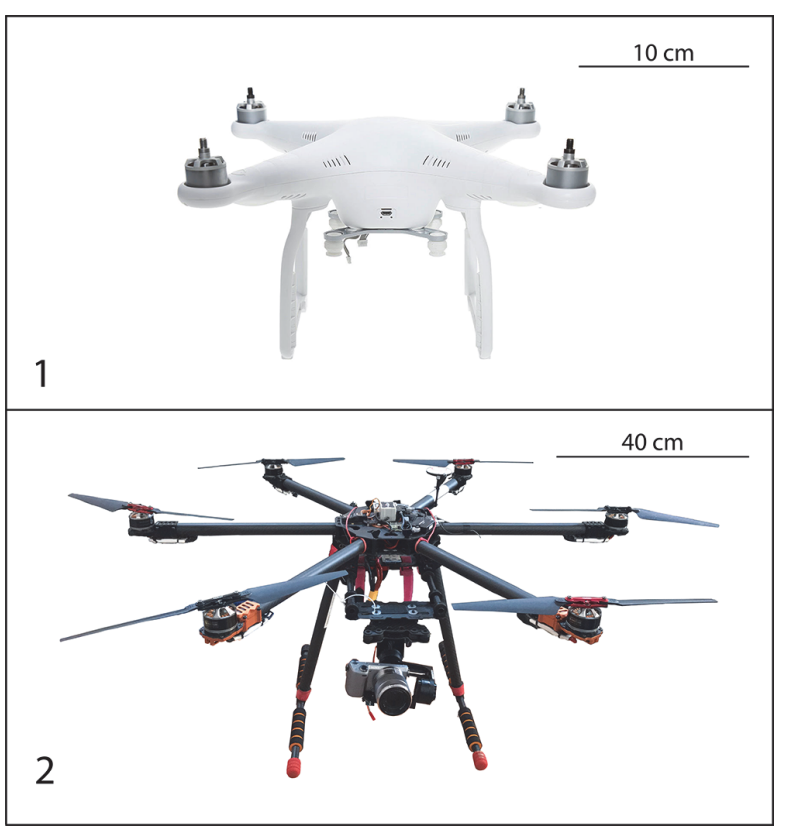

FIGURE 3. The UAVs (Unmanned Aerial Vehicles) used for aerial survey of the tracksite. 1, quadcopter SZ DJI Phantom 4; 2, hexacopter Tarot FY680 Pro.

sediments intensively burrowed by marine invertebrates (Fanti et al., 2014).

\section{EQUIPMENT AND METHODS}

Two field-campaigns were performed to generate high-resolution surface models, mosaicking and ortho-rectification products of the vast dinosaur track-bearing surface. All these products were obtained using both ground- and aerial-based photogrammetry.

\section{Aerial-based Photogrammetry}

Two different types of UAVs were used to perform the low altitude photogrammetric survey of the Molfetta tracksite: the quadcopter SZ DJI Phantom 4 (Figure 3.1) and the hexacopter Tarot FY680 Pro Brushless Motors (Figure 3.2).

The quadcopter SZ DJI Phantom 4 is a drone with a mounted smart camera that has a magnesium skeleton and a sleek aerodynamic design. It can be piloted using both a remote control and the TapFly feature that flies the aircraft toward the planned direction by tapping on a mobile device screen. The maximum horizontal translation speed is $20 \mathrm{~m} / \mathrm{s}$, maximum ascent speed is $6 \mathrm{~m} / \mathrm{s}$, and maximum descent speed is $4 \mathrm{~m} / \mathrm{s}$. Its weight (battery and propellers included) is $1.38 \mathrm{~kg}$. Through its 6 Ampere battery it can achieve approximately 28 minutes of maximum flight time. The quadcopter is equipped with a proprietary fixed digital onboard camera with 1/2.3" $20 \mathrm{Mpx}$ CMOS sensor, able to shoot $4 \mathrm{k}$ videos at up to 30 frames per second. The obtained videos and photos can be saved as MP4, MOV files (video) and JPEG, DNG files (photos).

The hexacopter Tarot FY680 Pro Brushless Motors has a carbon fiber composite structure. It can be piloted in manual mode using a remote control (with full flight control by the operator) in "Attitude" and "GPS" mode, with flight assisted by a control system and electronic sensors to stabilize the UAV (Wookong IMU and Wookong GPS both of DJI). The maximum horizontal translation speed is $15 \mathrm{~m} / \mathrm{s}$, maximum ascent speed is $6 \mathrm{~m} / \mathrm{s}$, and maximum descent speed is $4 \mathrm{~m} / \mathrm{s}$. The weight is about $9 \mathrm{~kg}$. The power is supplied by an $8 \mathrm{Amp}$ battery that gives the aircraft about 5 minutes of autonomous flight. The UAV can be controlled either by Flight Controller, in direct mode, or via the Ground Control Station, in automatic mode, with a planned flight. The hexacopter was equipped with a removable digital compact camera SONY NEX5R for aerial-photogrammetry with a CMOS sensor, able to capture photos with $16.1 \mathrm{Mpx}$.

Data acquisition: the UAV + GPS survey. The UAV photo aerial-based photogrammetric surveys were planned using specific software (DJI GO app installed on an Apple I Pad for quadcopter and DJI Ground Station installed on a rugged PC for hexacopter) that allows both UAVs to have autonomous flight. The two software packages allow the study area to be traced from satellite orthophotos and the flight plans uploaded with all the needed parameters to make correct and riskless flights. Depending on parameters such as flight altitude, horizontal and vertical speed of the aircraft, focal length and $\mathrm{H}$ (Height) and W (Width) parameters of the camera, lateral and longitudinal coverage of the frames, the software creates the required number of transects to get the planned survey. Processed transects indicate the path that the UAV will follow during the flight. Their spacing depends on the desired longitudinal coverage between a frame and the next one, and the transverse coverage between the same frame and the adjacent one. This process meets the requirements for creating an aerophotogrammetric model in stereoscopy.

The goal of the surveys was to obtain the overall map of the area, as well as an estimate of the number and size of the tracks and trackways, by analysing orthophotos and the digital elevation model (DEM) of the site. In order to test the change in resolution and accuracy of UAV's surveys with changing flight heights, two different surveys (the 
first one at $30 \mathrm{~m}$, the second one at $10 \mathrm{~m}$ ) were performed with the DJI Phantom 4, with almost windless atmospheric conditions. Camera parameters are fixed since the lens is a Fov $94^{\circ} 20 \mathrm{~mm}$ (35 $\mathrm{mm}$ equivalent) with $\mathrm{f} / 2.8$ focus at $\infty$. The number of photos taken was 74 for the first survey and 127 for the second one.

Given the autonomy of the Tarot FY680 hexacopter and the size of the area, three separate flight sessions were programmed, with flight durations of about 4 minutes each. Camera parameters added in the tool of the PC Ground Station are: focal length $=18 \mathrm{~mm}, \mathrm{H}=16 \mathrm{~mm}, \mathrm{~W}=24 \mathrm{~mm}$, flight height $=15 \mathrm{~m}$, longitudinal and transverse overlap between frames, respectively equal to $70 \%$ and $60 \%$. Based on the listed parameters, the software tracked three transects for each area with an expected number of shots of up to 80 per flight. The ground resolution was about $5 \mathrm{~mm}$. At the end of the survey, the number of photos taken was 250 .

The number of photos for each survey was automatically set up by the software of the drone in order to cover the entire surveyed surface. The spatial position of a set of established markers (recognizable in the photos) was measured using a GPS-based system in order to georeference orthophotos and DEMs. Ten circular markers with a diameter of $20 \mathrm{~cm}$ and 10 control points were surveyed in Real Time Kinematic (RTK) mode. The average error on the planar position of the marker's centre point was about $2 \mathrm{~cm}$.

Data processing and generation of 3D models. Data processing was carried out using a HP Z840 Workstation with Intel Xeon CPU E5-2620 v4, 2.1 $\mathrm{GHz}, 32$ GB RAM, AMD FirePro W5100 4 GB graphics and Windows 7 Pro as operating system. The processing of digital images was made using the Agisoft PhotoScan ${ }^{\circledR}$ Pro software, following the procedure established by Mallison and Wings (2014). This software, through a series of distinct steps, allows the derivation of three-dimensional models and other products such as point clouds, DEMs, and orthophotos, which can be integrated with GIS products. In the present study, the data analysis and derivation process were carried out as follows: 1) uploading photos; 2) aligning photos; 3 ) creating point clouds; 4) positioning markers; 5) mesh and texture creation; 6) DEM and orthophoto generation and building; 7 ) exportation of DEM and orthophoto.

\section{Ground-based Photogrammetry}

An 18.1-megapixel digital single-lens reflex camera (DSLR) Canon EOS 1200D was used for the high-resolution digital photogrammetry. The camera mounts an 18.0 Megapixel CMOS (APS-C) image sensor and is equipped with a Canon EF lens and a Canon DIGIC 4 image processor. It has 9-point AF points and ISO can be set from 100 to 6400 (Expandable to $\mathrm{H}: 12800$ ). The files are in RAW and JPEG file formats, and in .MOV for the Full HD video recording.

Data acquisition. To obtain the most accurate virtual model for each analyzed footprint, 56 photos were taken, divided in three photosets from three different points of view (ground level, camera dipping $30^{\circ}$ and $60^{\circ}$ with respect to the quarry surface). A caliber was placed close to the footprint in order to scale the 3D models. Each photo was captured at a distance of approximately $1 \mathrm{~m}$, turning around every $15^{\circ}$ in order to reach an overlap rate for each consecutive photo of at least $30^{\circ}$. The camera was set to autofocus with ISO on 100; shutter speed and aperture were set manually depending on lighting conditions. The photos were taken between 10 a.m. and 5 p.m. (March 2017) in order to catch adequate sunlight, and were exported as JPEG files with $5184 \times 3456$ pixel resolution at $72 \mathrm{dpi}$. The close-range photogrammetry product consists of 20 three-dimensional models belonging to five distinct trackways not displayed in this paper, but that will be used for a work in preparation on the ichnological description of the site.

Data processing. Data processing was carried out using a PC Intel $\AA$ Core i5-660, with 16,00 GB RAM and Windows 10 as an operating system. To create 3D models, the same software of aerialbased photogrammetry was used (Agisoft PhotoScan ${ }^{\circledR}$ Pro), and we proceeded by following the same steps described for the aerial-based photogrammetry. We analyzed photos, discarding those with low resolution or out of focus, to reduce the processing time. At the end, for every footprint, we chose 52 photos on average.

On each footprint models, five markers were positioned on the mesh surface in order to scale and orientate the 3D model with an accuracy of $0.001 \mathrm{~m}$ and an error of $0.015 \mathrm{~m}$. To orientate the surface perpendicularly to the $Z$ axis and produce a Digital Elevation Model, three markers were placed on ground level at approximately the same altitude. To each landmark we assigned the 0 value to the $Z$ coordinate, to orientate the entire model perpendicularly to the trampled surface. 
TABLE 1. Technical parameters of the four different analyses performed on the Molfetta tracksite.

\begin{tabular}{lcccc}
\hline \multicolumn{1}{c}{ UAV model } & Tarot FY680 Pro & DJI Phantom 4 & DJI Phantom 4 & CR Photogr. \\
\hline Height (m) & 15 & 10 & 30 & 1 \\
Coverage area (sq m) & 3880 & 1770 & 10900 & 3.25 \\
Data collection duration (min) & $12^{\prime}$ (3 flights of 4') & $60^{\prime} 30^{\prime \prime}$ & $4^{\prime}$ ' 30" & $10^{\prime}$ \\
Processing time & $9 \mathrm{~h}$ & $5 \mathrm{~h}^{\prime} 30^{\prime}$ & $4 \mathrm{~h}$ & $9 \mathrm{~h}$ \\
Dense point cloud number & 109 & 35 & 25 & 17 \\
(millions) & & & & 5248923.0769 \\
Point density (pt/sq m) & 28092.7835051547 & 19774.011299435 & 2293.5779816514 & 0.43648055 \\
Average linear distance between & 5.96 & 7.11 & 20.88 & $9666 \times 9327$ \\
points (mm) & & & & 0.261 \\
Ortophoto resolution (pixel) & $17687 \times 12750$ & $10759 \times 11207$ & 14 & $4873 \times 4846$ \\
Ortophoto pixel size (mm) & 3.75 & 4.57 & $6381 \times 4817$ & 0.521 \\
DEM resolution (pixel) & $23101 \times 21897$ & $6089 \times 6453$ & 28.2 & 0.261 \\
DEM pixel size (mm) & 7.5 & 9.15 & 25 & \\
Ground resolution (mm) & 5 & 10 & & \\
\hline
\end{tabular}

\section{RESULTS}

\section{Aerial-based Photogrammetry}

UAV photo aerial-based photogrammetry, performed on the surface that preserves the tracks, allows us to detect, with different degrees of detail, the main ichnological features of the dinosaur trackways in the San Leonardo quarry. In spite of the application of the same photogrammetric method, the use of two UAVs having different characteristics, and the choice of different flight heights, led to the recording of high-resolution digital data that differ in terms of both image, digital surface model and ground resolutions. Details of the remote sensing results are summarized in Table 1 and in the electronic Supplemental Material. In Figure 4 , details of a selected sector of the trampled surface are shown in order to have a visual comparison of the resolution obtained from the three surveys.

The survey performed with the quadcopter DJI Phantom 4 at a flight height of $30 \mathrm{~m}$ (flight duration: 4' 30") covered an area of $10,900 \mathrm{~m}^{2}$, which exceeds the trampled surface boundary and almost corresponds to the entire quarry. During a processing time of about $4 \mathrm{~h}$, a 3D model was obtained from 74 overlapping pictures made up of a dense point cloud having 25 million points. The last phase of the processing activity was the production of an orthophoto raster map and a DEM raster map showing a fairly good image and ground resolution. The orthophoto map, made up of $9382 \times 7016$ pixels with a pixel size of $14 \mathrm{~mm}$, allows us to recognize all main trackways recorded on the upper quarry surface (Figure 4.1). In spite of this, the DEM resolution (Figure 4.2), made up of $6381 \times 4817$ pixels with a pixel size of $28.2 \mathrm{~mm}$, and the slope raster map, classified in 10 classes (Figure 4.3), clearly show a lack of detail on single footprints since the ground resolution is about $25 \mathrm{~mm}$, not enough for recognizing their accurate morphology.

The second survey performed with the quadcopter DJI Phantom 4 at a flight height of $10 \mathrm{~m}$ covered, in about 6' 30 ", an area of $1,770 \mathrm{~m}^{2}$, not including the entire trampled surface. After a processing time of about 5h 30', a 3D model was generated from 127 overlapping pictures made up of a dense point cloud having 35 million points. This model allowed us to export an orthophoto raster map with good resolution $(10759 \times 11207$ pixels with a pixel size of $4.57 \mathrm{~mm}$ ) (Figure 4.4). In the image, all the trackways enclosed in the surveyed area are easily distinguishable; in addition, the detail of single tracks is significantly better than the one obtained with the previous survey. The DEM resolution $(6089 \times 6453$ pixels with a pixel size of 9.15 $\mathrm{mm}$ ) (Figure 4.5) and the slope raster map (Figure 4.6) show sufficiently detailed morphological features of the footprints that we were able to distinguish between carnivore and herbivore tracks. This definition is the result of a ground resolution of about $10 \mathrm{~mm}$.

The last survey was performed with the hexacopter at a flight height of $15 \mathrm{~m}$. It covered, by merging three different flight sessions of 4' each, an area of $3,880 \mathrm{~m}^{2}$ that nearly corresponds to the entire trampled surface. After a processing time of 

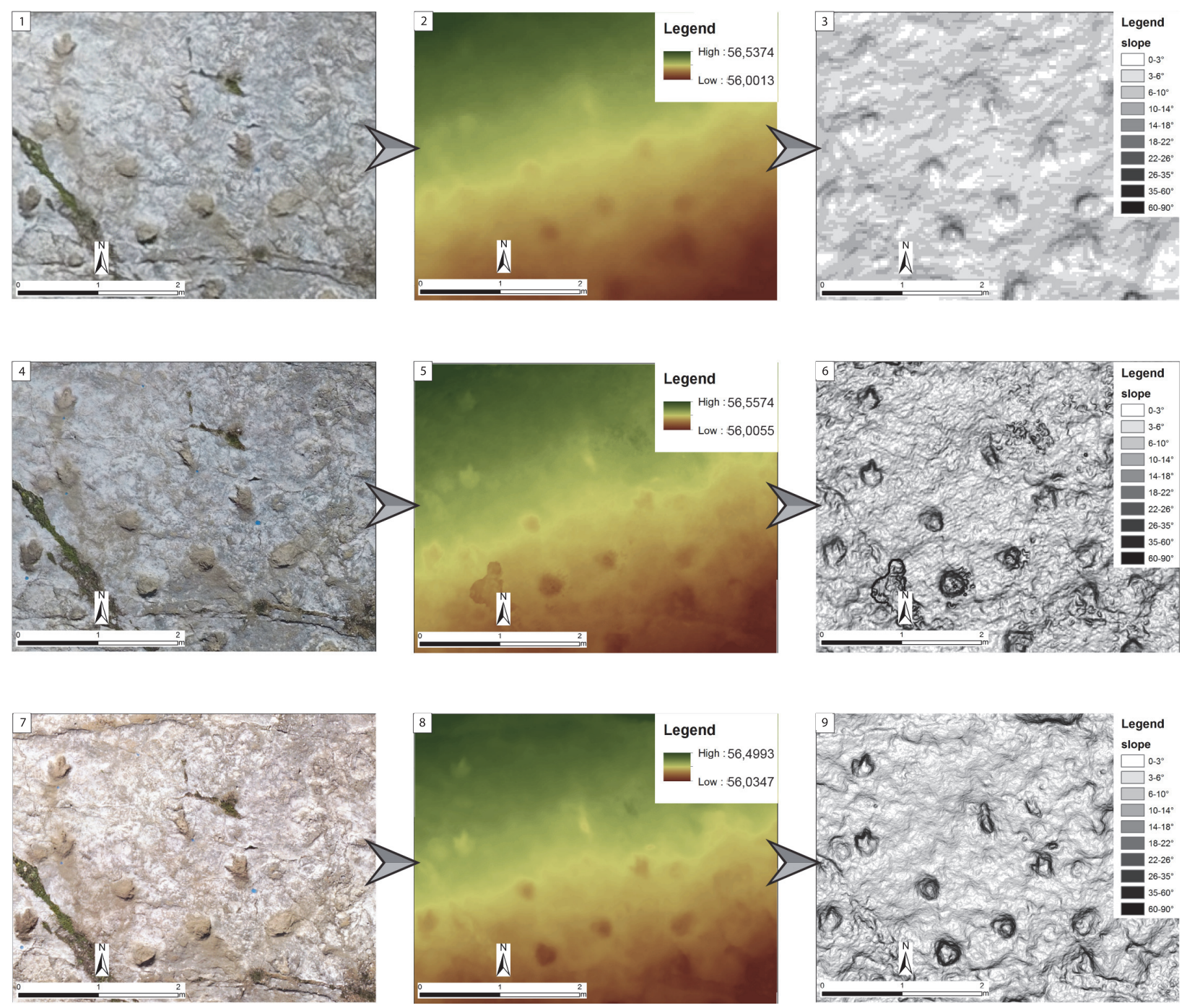

FIGURE 4. Comparison of the results obtained on a sample area. 1, orthophoto; 2, DEM; 3, slope raster map produced by the quadcopter at flight height of $30 \mathrm{~m}$; 4, orthophoto; 5, DEM; 6, slope raster map produced by the quadcopter at a flight height of $10 \mathrm{~m} ; 7$, orthophoto; 8, DEM; 9, slope raster map produced by the hexacopter at a flight height of $15 \mathrm{~m}$.

about 9h, a 3D model was generated from 183 overlapping pictures made up of a dense point cloud having 109 million points. The orthophoto raster map shows an excellent resolution (17687x12750 pixels with a pixel size of $3.75 \mathrm{~mm}$ ) (Figure 4.7). Unfortunately, the process of merging three different photomosaics led to the formation of a couple of holes in the orthophoto and in the DEM. The orthophotomosaic clearly shows all the trackways and the single footprints with a slightly higher detail than the one shown by the second survey with the quadcopter. Moreover, the DEM (Figure 4.8) shows an excellent resolution (23101x21897 pixels with a pixel size of $7.5 \mathrm{~mm}$ ), and the processed slope raster map of the surface
(Figure 4.9) outlines the significantly high morphological detail reached for single footprints corresponding to a ground resolution of about $5 \mathrm{~mm}$.

The high-resolution orthophoto obtained by means of aerial photogrammetry using the hexacopter has an average accuracy in the planimetric positioning of about $4 \mathrm{~cm}$. It was obtained by comparing the GCP GPS data with those gained from their positioning on the orthophoto. The DEM has an average accuracy of the altimeter data of about $1 \mathrm{~cm}$. This value was obtained by comparing the GCP GPS data with the data obtained from DEM. Given the quality of orthophoto and DEM, the two products were exported in formats compatible with 

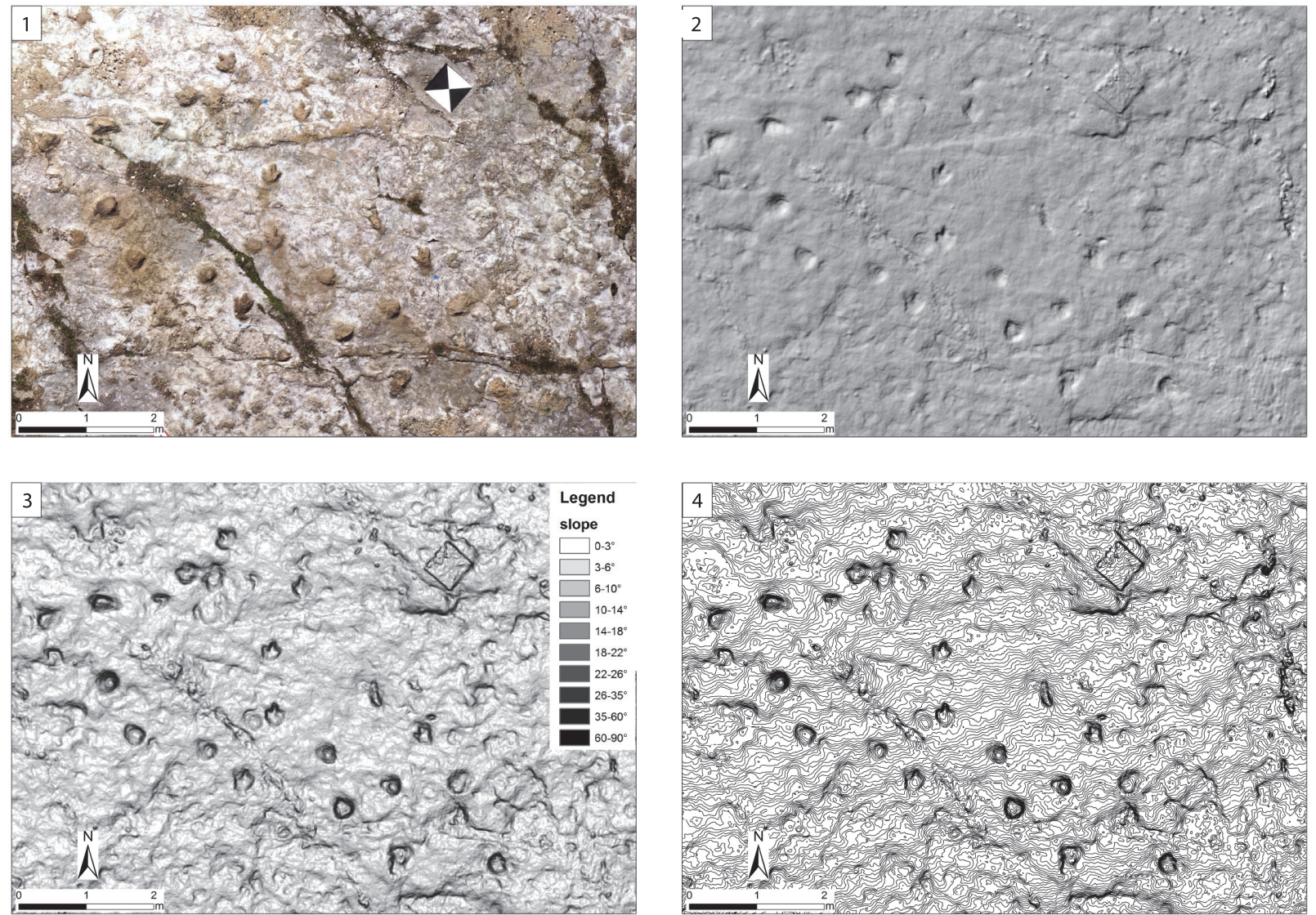

FIGURE 5. Comparison of the products generated for one of the most trampled sector. 1, orthophoto raster map; 2, hillshade raster map; 3 , slope raster map; 4 , contour lines vector map.

GIS platforms to make them available for the subsequent ichnological analysis (.TIFF).

Two sectors of the trampled surface are shown in Figures 5 and 6 . The first sector shows the detail of the orthophoto raster map (Figure 5.1), hillshade raster map (Figure 5.2), slope raster map (Figure 5.3), and contour lines vector map (Figure 5.4). According to the ground resolution, contour lines are drawn every $5 \mathrm{~mm}$. The second sector shows the detail of the orthophoto raster map (Figure 6.1), hillshade raster map (Figure 6.2), slope raster map (Figure 6.3), and contour lines vector map (Figure 6.4) of the L-shaped tetrapod track. Contour lines are drawn every $10 \mathrm{~mm}$. Since the last survey shows the best resolution, it was used to derive an orthophotomosaic of the whole trampled surface (Figure 7).

\section{Ground-based Photogrammetry}

Captured photos (about 56 for each track) covered an area of about $3.25 \mathrm{~m}^{2}$, roughly corresponding to the two sample footprints (Figure 8).
They were interpolated and processed in highquality accuracy, in order to obtain a sparse cloud with at least 18,000 points. Processing time was about $9 \mathrm{~h}$, and the created 3D model is made up of a dense point cloud having 17 million points. Finally, a mesh with at least 2.5 million faces was produced, and a texture was applied to the 3D models. The 3D models were exported as OBJ files, the texture and contour lines as JPEG files and the DEM as a TIFF. To analyze the DEM and to produce the final images, Surfer and CloudCompare software were used.

After orienting the model, the contour lines and the DEM of each single footprint were generated from the dense cloud. The contour lines have an equidistance of $3 \mathrm{~mm}$. The obtained orthophoto has an ultrahigh resolution (9666x9327 pixels with a pixel size of $0.261 \mathrm{~mm}$ ). The extremely high image resolution allows us to distinguish all the detailed morphological features of the analysed footprints, such as number of digit traces, digital pad impressions, and claw or hoof marks, not detectable in the orthophotomosaics produced with 

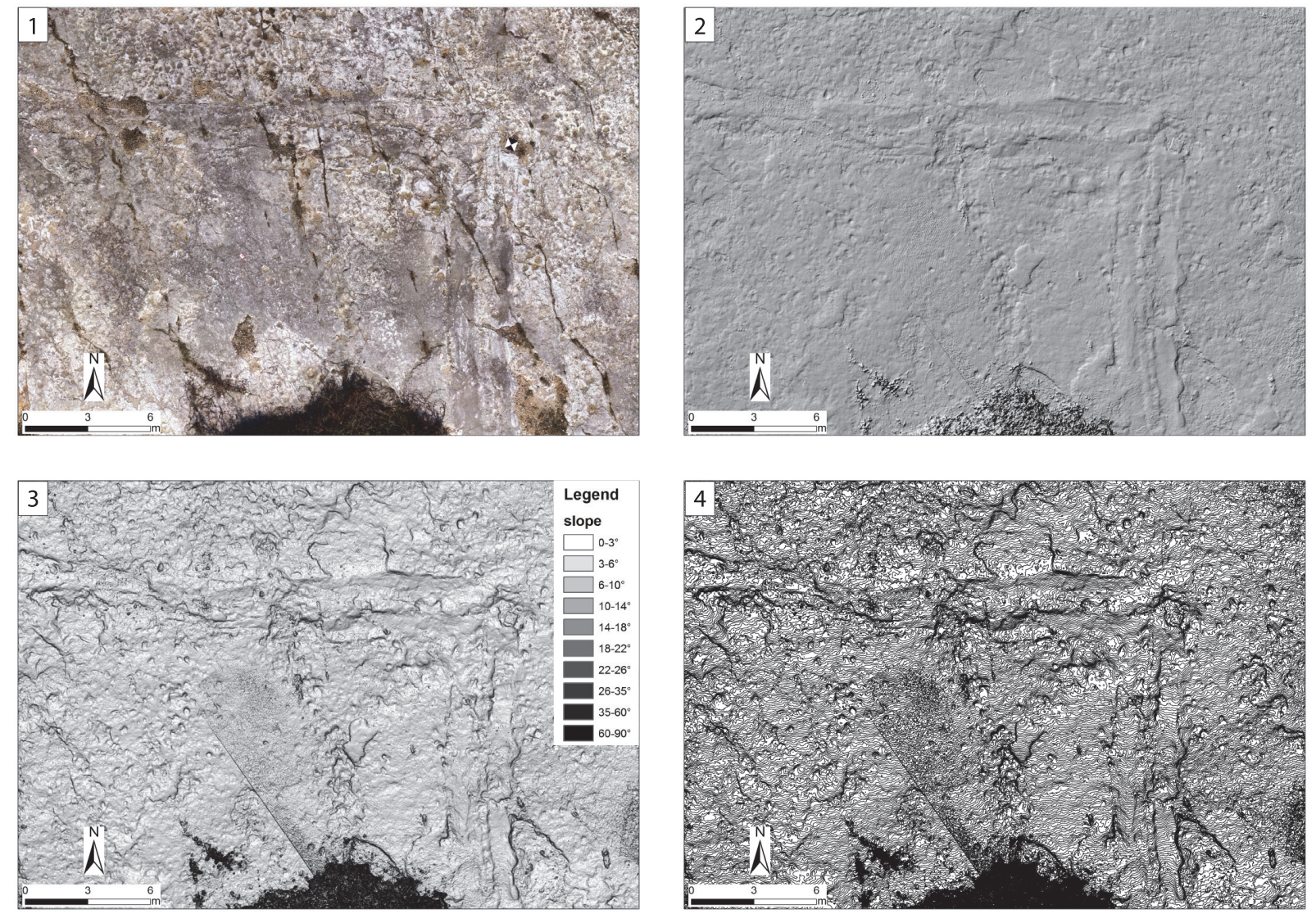

FIGURE 6. Comparison of the products generated for the sector including the "L-shaped trace". 1, orthophoto raster map; 2, hillshade raster map; 3 , slope raster map; 4, contour lines vector map.

quad- and hexacopter. The DEM shows also a good resolution $(4873 \times 4846$ pixels with a pixel size of $0.521 \mathrm{~mm}$ ).

\section{DISCUSSION}

The application of aerial and ground-based photogrammetry to ichnological studies is becoming increasingly frequent (Romilio et al., 2017). Based on the different surveys described above, we here provide a discussion of the obtained data at the Molfetta dinosaur tracksite, aimed at understanding the impact of these new techniques on ichnology, and on the study, preservation and valorisation strategies of ichnological heritages.

The Phantom 4 quadcopter has an extreme practicality and rapidity of execution that allows imaging of a $2700 \mathrm{~m}^{2}$ surface in a few minutes. Its flight autonomy of more than 20 minutes is sufficient to cover the entire trampled surface with only one flight and the resolution of the obtained models ranges from reliable to extremely accurate (depending on the flight height). The two quadcop- ter surveys (at low and medium altitudes) produced DEMs and orthophotos that do not show substantial differences in terms of resolution. The better values are all predictable if one takes into account that the model obtained with the average flight height of $30 \mathrm{~m}$ is the one based on a smaller number of photos. Finally, it is worth noting that the Phantom 4 quadcopter costs and maintenance are affordable. However, the use of the Phantom 4 UAV to generate DEMs and orthophotos of a large tracksite could suffer drawbacks such as the atmospheric conditions. The low-altitude aerial surveys can be performed only under ideal atmospheric conditions; a windless day is thus crucial to produce high-quality data (wind less than $10 \mathrm{~m} / \mathrm{s}$ according to the DJI specs). Moreover, at a medium flight height of $30 \mathrm{~m}$, the resolution is suitable only for large-scale analysis and not for smallscale investigations for which close-range photogrammetry is undoubtedly preferable. The fixed focal length is another severe limitation if, for instance, the occurrence of obstacles at low flying heights (10 $\mathrm{m}$ in the present study) limits the lateral 


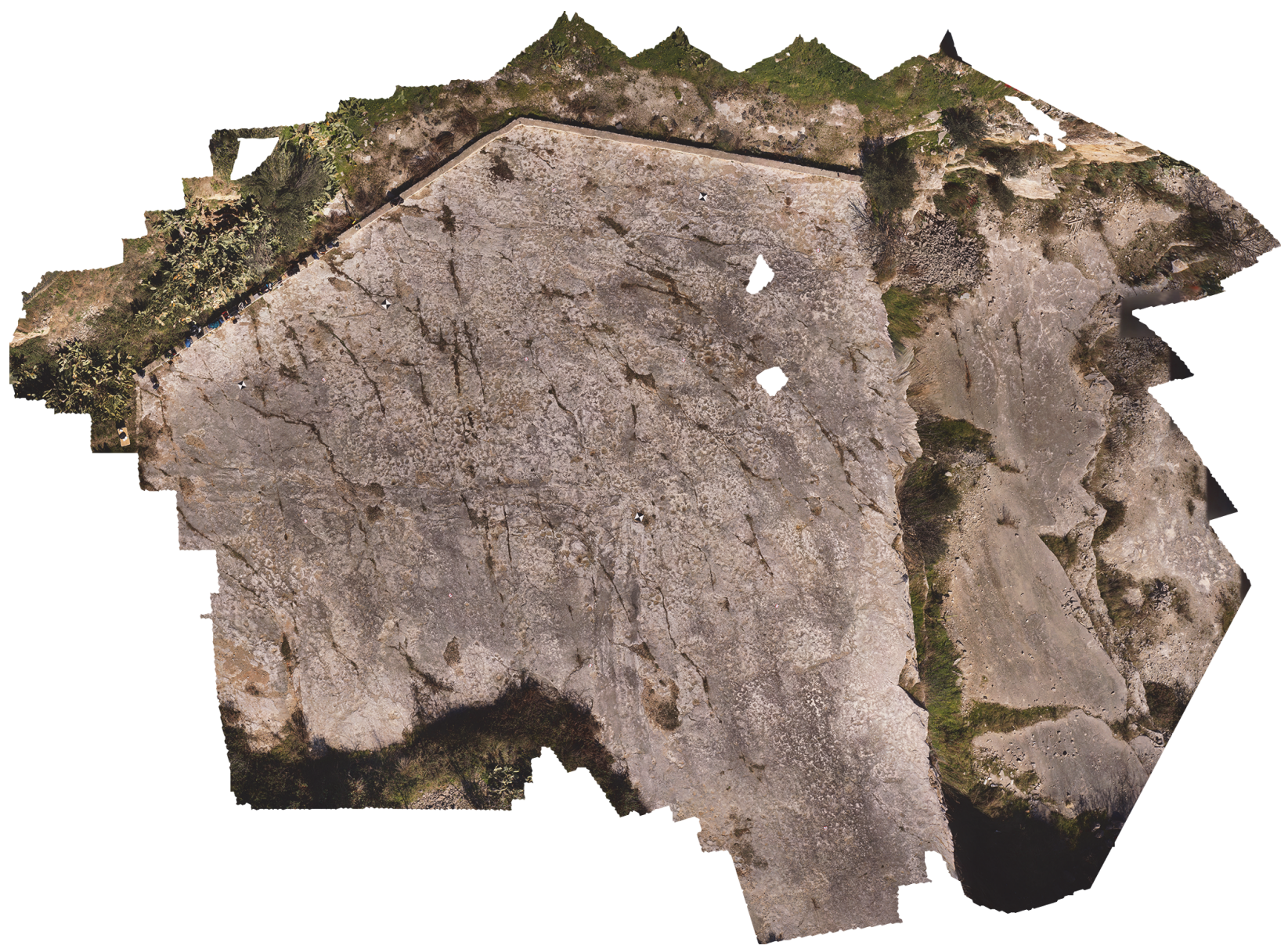

FIGURE 7. Orthophotomosaic of the Molfetta tracksite produced by the aerial survey performed with the hexacopter.

flying area preventing the survey of the entire trampled surface.

The Tarot FY680Pro hexacopter is heavier than the DJI Phantom 4 quadcopter and thus it is more wind-resistant. This feature allows to obtain accurate data also during windy days. The highquality mounted camera, equipped with a variable focal length, allows the capture of very high resolution orthophotos and DEMs even flying at a flight height of $15 \mathrm{~m}$ above the surface and with the camera positioned orthogonally to the trampled horizons. The variable focal length of the camera allows the zoom to be adapted according to the selected flight height, and to preserve the general quality of data. This allows the selection of safe flight heights, above obstacles, without losing resolution. The photomosaic clearly shows all the footprints, at least enough to draw their gross outlines. According to the ground resolution, contour lines can be traced at $5 \mathrm{~mm}$, instead of $10 \mathrm{~mm}$ or $25 \mathrm{~mm}$ of models obtained using Phantom 4 quadcopter, proving the higher resolution of Tarot hexacopter even if compared with low-altitude flight products.
This result was obtained with a lower resolution camera (16.1 Mpx versus $20 \mathrm{Mpx}$ of the camera mounted on the quadcopter), but with double the number of photos (250) collected for each flight, in comparison to the model produced with DJI at 10 $\mathrm{m}$ of altitude (127). Finally, in the models produced by the hexacopter it is easy to detect and outline other features of the trampled surfaces, such as bedding and fractures likely due to tectonics. Nevertheless, the Tarot FY680Pro hexacopter also presents some weak points such as its greater size and weight compared to those of DJI Phantom 4 quadcopter. Its flight duration is less than 5 minutes, which entails increased energy consumption. It takes three batteries to perform the survey of an area of $2700 \mathrm{~m}^{2}$ during three distinct flight sessions. As a result, the orthophotomosaic may show uncovered areas (e.g., holes in the orthophoto), in that DEMs and orthophotos are produced by merging pictures taken during three flights. Finally, the hexacopter costs and maintenance are more expensive compared to quadcopter, and captured 


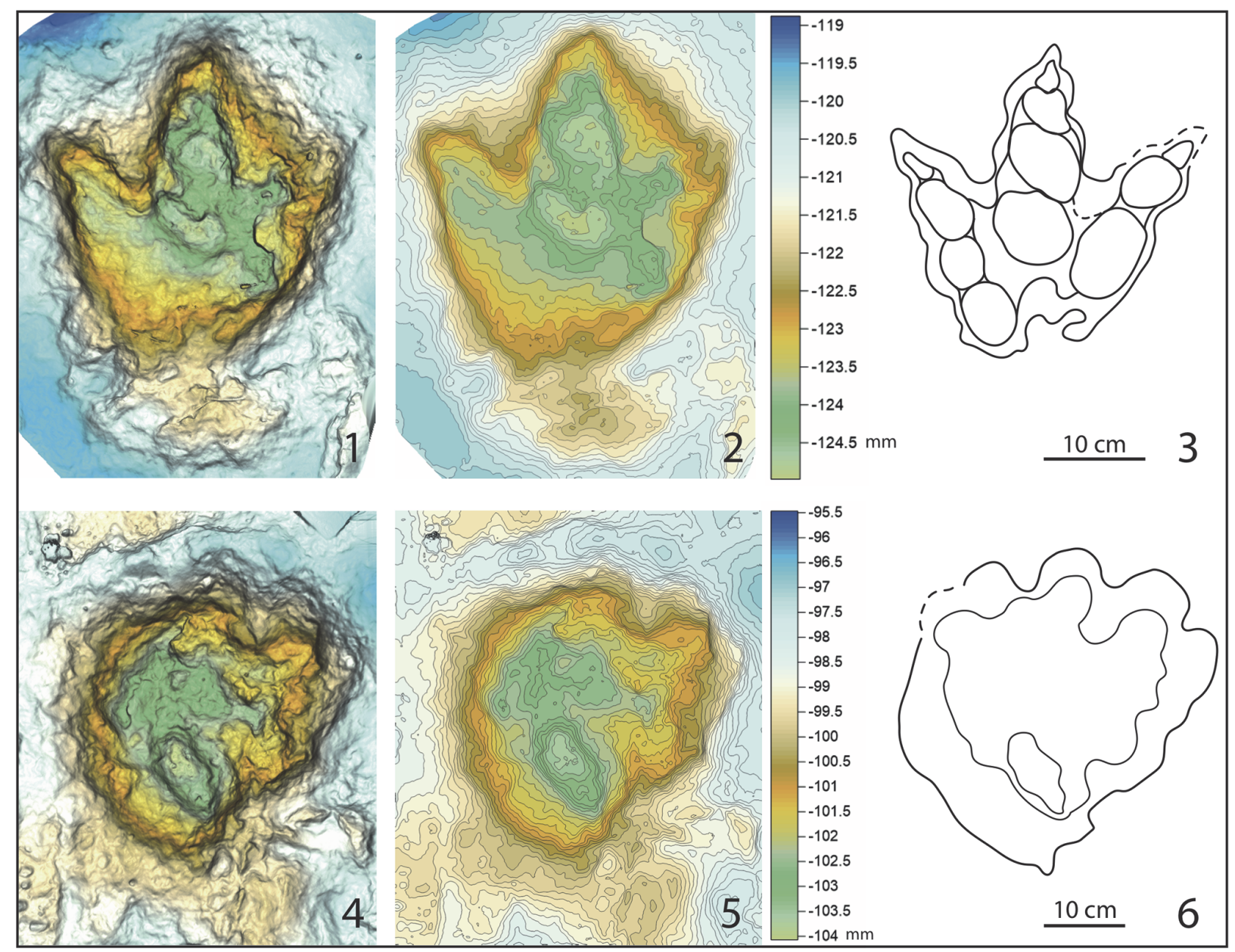

FIGURE 8. Molfetta dinosaur tracks, photogrammetry derived 3D models and interpretations; 1-2, DEM and contour line map of a theropod footprint (contour lines have an interval of $0.2 \mathrm{~cm}$ ); 4-5, DEM and contour line map of an ornitischian footprint; 3 and 6 , interpretative outline drawings of the studied tracks.

images need high-performance hardware for processing and acquisition.

Ground-based photogrammetry produced ultrahigh-resolution images as shown in Table 1 and Figure 8 (average linear distance between points $0.43 \mathrm{~mm}$, ground resolution $0.261 \mathrm{~mm}$ ). Data acquisition for each investigated track is extremely rapid (10 minutes). All images can be accurately investigated by means of software that allows users to tilt and zoom into the 3D model, resulting in track observation, analysis and measurements in support of the classic analysis performed on the site. The opportunity of changing and orienting light, adequately and univocally for each track, prevents any type of error derived from original atmospheric and lighting conditions. The method provides the opportunity to study footprints as accurately as in the field, but with a higher accuracy and with ideal lighting conditions for an unlimited number of times.
The UAV-based photogrammetry, applied to the survey Molfetta ichnological site has, therefore, proved to be ideal for a photographic coverage of a large trampled area, useful to obtain a detailed map and a georeferenced vision of the dinosaur tracks preserved on the ground. In addition, the 3D models derived from the processing of point clouds provide a faithful reproduction of tracks and trackways in their plano-altimetric components, on which it was possible to carry out accurate measurements. UAV-derived images also help the preparatory analysis of an ichnosite, helping to identify areas that will require in-depth field studies. The repetition of flights with identical parameters also allows the possibility of multi-temporal analyses aimed at monitoring the conservation conditions of a site. In addition, the use of drones allows for the capture of reliable and high-resolution images comparable to those obtained by terrestrial laser scanners and manned aerial photogrammetry, but 
with reduced working costs and rapid execution time.

Close-range photogrammetry models provide extremely detailed information, allowing careful analysis of morphological characters such as digital pad impressions, heel traces, claw hoof traces, and consequently increasingly reliable ichnotaxonomical assignments and ichnosystematic attributions. All these details were recognized in the 3D images that provide a hyper-realistic experience with their restitution of contour lines and colour coded images.

The coupling of ground- and aerial-based photogrammetry, therefore, allows the generation of several products (i.e., 3D models, videos, etc.) that can be used by researchers to make new inspections of the site without the need to be onsite, as well as for conservation and dissemination purposes. The long-term conservation of the geopaleontological heritage has been, and still is, one of the most debated issues by geologists around the world. Despite numerous experiments with new methods of documentation and restoration of geosites, the problem of their management and conservation still persists in all its aspects.

In addition to contributing to the development of a sustainable economy, the protection and valorisation of the geopaleontological heritage of different regions contribute to improving geosciences, education, and public awareness and to promoting geo-tourism. The knowledge and protection of geopaleontological heritage contribute to sustaining the competitiveness of a territory in the cultural, social, and economic fields, thus offering multiple development prospects. Palaeontological sites can be "exploited" not only for their scientific component, but above all for their social and economic value, in a framework of environmental sustainability. In this sense, the information technologies described here can be crucial for the enhancement and use of these cultural heritages.

\section{CONCLUSIONS}

The mapping of large dinosaur tracksites has been accomplished using field data and/or aerial photos captured with different manned or unmanned (helicopters, balloons, gliders) aerial vehicles. The recent introduction of a number of UAVs (quad-, hexa-, and octocopters) provides a new and powerful tool for mapping trampled surfaces showing dinosaur footprints. We reported the results of UAV photo-aerial photogrammetry performed at the Molfetta tracksite using two different drones, a quadcopter (Phantom 4) and an hexacopter (Tarot FY680). The goal of this paper was to evaluate the resolution and the reliability of the large-scale models obtained (DEMs and orthophotos) useful to create a detailed and georeferenced map and a visual contextualization of the ichnosite. Additionally, points in favour or disfavour for each drone, in terms of time, costs, and accuracy, were assessed. Parallel to these experiments we also performed ground-based photogrammetry to evaluate its impact on the ichnological analysis (ichnotaxonomy and ichnosystematics) in the light of the recent introduction of high-resolution digital cameras and powerful processing and interpretation software.

Post production was found to be relatively rapid and spatial positioning of markers detected by UAVs make the georeferencing of tracks and trackways more accurate than that obtained using a total station. The hexacopter can provide more accurate results (DEMs, orthophotos) than the quadcopter, even though models derived from this latter UAV have an acceptable accuracy, sufficient to make tracksite maps. The results obtained using a quadcopter allow for the identification and mapping of the main characters of the trampled surface (i.e., number and orientation of trackways, degree of trampling, etc.) and to "fly" over the surface using $4 \mathrm{~K}$ videos. To study a single footprint and to detect morpho-anatomical features of a track, the ground-based photogrammetry is preferable and highly recommended when possible. The introduction of new and more sophisticated digital cameras along with new processing software (Surfer, AgiSoft PhotoScan Pro) allows the capture of highresolution images and the creation of incredibly accurate models, more reliable than those obtained with drones. The coupling of ground- and aerial-based photogrammetry is still new in the study of dinosaur tracksites and the experiments tested to date allowed for the collection of data in order to define, in the future, a standard procedure to determine what is the best drone or digital camera to adopt, the optimal flight altitude, or the best software to use in the processing and post-processing phase.

Nevertheless the use of this integrated approach can make various tasks in ichnological analysis easier and has direct bearings on ichnological heritage managment: i) large-scale ichnosite description and mapping, ii) field activity planning, iii) safe investigation of areas with difficult accessibility (i.e., high elevation areas, steep slope); iv) improvement of ichnotaxonomic and ich- 
nosystematic analyses; v) ichnosite conservation and valorisation; vi) development of the prerequisites for sustainable conservation- and valorization-based geotourism.

The approach proposed in this study provides ichnologists with consistent, cheap, and rapid methodologies useful to study ichnosites both at the track and site scale. It is worth remembering that this approach does not substitute the standard analytical methods (field mapping, tracing on acetate overlays, casts), but can integrate with and improve them. Finally, photogrammetry can be used not only for scientific purposes, but also for promoting the geological and paleontological knowledge of geosites. For this purpose, the photogrammetric material could be used for educational programs and advertising documents (e.g., brochures, virtual site on the web, exhibition, and/ or outdoor panels). Moreover, all of the collected photogrammetric data could be used to propose a conservation strategy for the San Leonardo quarry geosite. In fact, since the trampled surface is exposed to a severe meteoric weathering, the created models, showing the present-day condition of the footprints, could be used for multi-temporal monitoring aimed at checking the status of the geosite over time.

\section{ACKNOWLEDGMENTS}

We thank the two anonymous reviewers for their helpful suggestions and comments that greatly improved the manuscript. We are also greatly indebted to the Piccininni and Caldarola families, who allowed free access to the quarry for geological and paleontological analyses. We wish to thank also the Soprintendenza Archeologica della Regione Puglia (Nucleo operativo di Bari), for authorizing field work and the Museo di Scienze della Terra of Bari University (SIMA- UNIBA) for data and samples storage.

Research funds were granted to Marcello Tropeano by the University of Bari (Fondi di Ateneo "Ricerche stratigrafico/sedimentologiche di base ed applicate per il riconoscimento, la gestione e la tutela delle georisorse e dei beni storico/culturali e geoambientali"). The research was also supported by "Principi Attivi 2009- Giovani idee per una Puglia migliore", a grant funded by the "Assessorato alla cittadinanza attiva Regione Puglia".

\section{REFERENCES}

Adams, T.L. and Breithaupt, B.H. 2003. Middle Jurassic dinosaurs of northern Wyoming: evidence from the Yellow Brick Road Dinosaur Tracksite, Bighorn Basin, Wyoming. Wyoming Geo-notes, 78:39-46.

Adams, T.L., Strganac, C., Polcyn, M.J., and Jacobs, L.L. 2010. High resolution threedimensional laser-scanning of the type specimen of Eubrontes (?) glenrosensis Shuler, 1935, from the Comanchean (Lower Cretaceous) of Texas: implications for digital archiving and preservation. Palaeontologia Electronica, 13.3.1T:11p, http://palaeo-electronica.org/2010_3/ 226/index.html

Avanzini, M., Franceschi, M., Petti, F.M., Girardi, S., Ferretti, P., and Tomasoni, R. 2008. New Early Jurassic (Hettangian-Sinemurian) sauropodomorph tracks from the Trento carbonate Platform (Southern Alps, Northern Italy). Studi Trentini di Scienze Naturali, Acta Geologica, 83:317-322.

Bates, K.T., Breithaupt, B.H., Falkingham, P.L., Matthews, N.A., Hodgetts, D., and Manning, P.L. 2009. Integrated LiDAR \& photogrammetric documentation of the Red Gulch Dinosaur Tracksite (Wyoming, USA). Proceedings of the Eighth Conference on Fossil Resources, 101103.

Bates, K.T., Rarity, F., Manning, P.L., Hodgetts, D., Vila, B., Oms, O., Galobart Lorente, À., and Gawthorpe, R.T. 2008. High-resolution lidar and photogrammetric survey of the Fumanya dinosaur tracksites (Catalonia): implications for the conservation and interpretation of geological heritage sites. Journal of the Geological Society, 165:115-117. https://doi.org/ 10.1144/0016-76492007-033.

Breithaupt, B.H. and Matthews, N.A. 2001. Preserving paleontological resources using photogrammetry and geographic information systems. In Crossing Boundaries in Park Management: Proceedings of the 11th Conference on Research and Resource Management in Parks and Public Lands. The George Wright Society, Inc. 
Breithaupt, B.H., Matthews, N.A., and Noble, T.A. 2004. An integrated approach to threedimensional data collection at dinosaur tracksites in the Rocky Mountain west. Ichnos, 11:1126. https://doi.org/10.1080/10420940490442296

Breithaupt, B.H., Southwell, E.H., Adams, T.L., and Matthews, N.A. 2001. Innovative documentation methodologies in the study of the most extensive dinosaur tracksite in Wyoming, p. 113-122. In United States Department of Interior-National Park ServicesGeological Resources Division.

Chapman, R.A., Anderson, A., Breithaupt, B.H., and Matthews, N.A. 2012. Technology and the study of dinosaurs, p. 247-272. In Brett-Surman, M.K., Holtz, T.R., Jr. and Farlow J.O. (eds.), The Complete Dinosaur. 2nd Edition. Indiana University Press, Bloomington, Indiana.

Cipriani, A., Citton, P., Romano, M., and Fabbi, S. 2016. Testing two open-source photogrammetry software as a tool to digitally preserve and objectively communicate significant geological data: the Agolla case study (Umbria-Marche Apennines). Italian Journal of Geosciences, 135(2):199-209. https://doi.org/10.3301/IJG.2015.21

Citton, P., Romano, M., Carluccio R., D’Ajello Caracciolo, F., Nicolosi, I., Nicosia, U., Sacchi, E., Speranza, G., and Speranza F. 2017. The first dinosaur tracksite from Abruzzi (Monte Cagno, Central Apennines, Italy). Cretaceous Research, 73:47-59. https://doi.org/10.1016/ j.cretres.2017.01.002.

Conti, M.A., Morsilli, M., Nicosia, U., Sacchi, E., Savino, V., Wagensommer, A., Di Maggio, L., and Gianolla, P. 2005. Jurassic dinosaur footprints from Southern Italy: footprints as indicators of constraints in paleogeographic interpretation. Palaios, 20(6):534-550. https:// doi.org/10.2110/palo.2003.p03-99

Falkingham, P.L. 2012. Acquisition of high resolution three-dimensional models using free, opensource, photogrammetric software. Palaeontologia Electronica, 15.1.1T:15p; palaeoelectronica.org/content/issue-1-2012-technical-articles/92-3d-photogrammetry

Falkingham, P.L., Bates, K.T., and Farlow, J.O. 2014. Historical photogrammetry: Bird's Paluxy River dinosaur chase sequence digitally reconstructed as it was prior to excavation 70 years ago. PLoS ONE, 9:e93247. https://doi.org/10.1371/journal.pone.0093247.

Fanti, F., La Perna, R., Minervini, L., Petruzzelli, M., Sabato, L., Spalluto, L., and Tropeano, M. 2014. Le orme di dinosauro di Cava San Leonardo (Molfetta). In Paleodays 2014: Field trip guide, 19-31. ISBN 978-88-88793-54-2.

Field, S., Waite, M., and Wandsnider, L. 2017. The utility of UAVs for archeological surface survey: A comparative study. Journal of Archeological Science: Reports, 13:577-582. https:// doi.org/10.1016/j.jasrep.2017.05.006

Fiore, A., Gallicchio, S., Giandonato, P.B., lurilli, V., Mastronuzzi, G., Pieri, P., Sabato, L., Sansò, P., Selleri, G., Simone, O., Sollitto, D., Tropeano, M., and Valletta, S. 2010. II patrimonio geologico della Puglia. Territorio e Geositi. Geologia dell'Ambiente, Suppl. 4:1-160.

lannone, A., Petruzzelli, M., and La Perna, R. 2012. La cava ad orme di dinosauro di Molfetta: opportunità di tutela, valorizzazione e divulgazione di una singolarità geologicopaleontologica del territorio. Geologia e Territorio, 2:17-21.

Lallensack, J.N., Sander P.M., Knötschke, N., and Wings, O. 2015. Dinosaur tracks from the Langenberg Quarry (Late Jurassic, Germany) reconstructed with historical photogrammetry: evidence for large theropods soon after insular dwarfism. Palaeontologia Electronica, 18.2.24A:34p, https://palaeo-electronica.org/content/2015/1166-langenberg-tracks

Lallensack, J.N., Van Heteren, A.H., and Wings, O. 2016. Geometric morphometric analysis of intratrackway variability: a case study on theropod and ornithopod dinosaur trackways from Munchehagen (Lower Cretaceous, Germany). PeerJ, 4:e2059. https://doi.org/10.7717/ peerj.2059.

Mallison, H. and Wings, O. 2014. Photogrammetry in paleontology: a practical guide. Journal of Paleontological Techniques, 12:1-31.

Mastronuzzi, G., Valletta, S., Damiani, A., Fiore, A., Francescangeli, R., Giandonato, P.B., lurilli, V., and Sabato, L. 2015. Geositi della Puglia, p. 394. In Ricognizione e verifica dei geositi e delle emergenze geologiche della Regione Puglia. Graphic Concept Lab, Bari. ISBN 9788890671685

Matthews, N.A. and Breithaupt, B.H. 2001. Close-range photogrammetric experiments at Dinosaur Ridge. The Mountain Geologist, 38:147-153.

Matthews, N.A. and Breithaupt B.H. 2011a. 3D image capture and close-range photogrammetry: an overview of field capture methods, p. 32-39. In Bonde, J.W. and Milner, A.R.C. (eds.), 
Field Trip Guide Book 71st Annual Meeting of the Society of Vertebrate Paleontology. Paleontological Papers Number 1. Nevada State Museum, Carson City, Nevada.

Matthews, N.A. and Breithaupt, B.H. 2011b. Moccasin Mountain tracksite, p. 55-62. In Bonde, J.W. and Milner, A.R.C. (eds.), Field Trip Guide Book 71st Annual Meeting of the Society of Vertebrate Paleontology. Paleontological Papers Number 1. Nevada State Museum, Carson City, Nevada.

Matthews, N.A. and Breithaupt, B.H. 2012. Taking measure of geospatial technology: innovations in close-range photogrammetry for 3D ichnology, p. 41. In Richter, A. and Reich, M. (eds.), Dinosaur Tracks 2012. An international Symposium, Obernkirchen, April 14-17, 2011, Abstract Volume and Field Guide to Excursions. Universitätverlag, Universitätsdrucke, Göttingen.

Matthews, N.A., Noble, T.A., Brady, L.R., and Breithaupt, B.H. 2014. Up, up and away: the use of unmanned aircraft systems for paleontological documentations, p. 231-239. In Santucci, V.L., Ligget, G.A., Beasley, B.A., McDonald, H.G., Tweet, J.S., Chilstrom, J., Foss, S.E., and Shelton, S.Y. (eds.), Protecting the Past, Managing the Present, Planning for the Future: Proceedings of the Tenth Conference on Fossil Resources. Dakoterra 6.

Matthews, N.A., Noble T.A., and Breithaupt, B.H., 2006. The application of photogrammetry, remote sensing and geographic information (GIS) to fossil resource management. New Mexico Museum of Natural History and Science Bulletin, 34:119-131.

Matthews, N., Noble, T., and Breithaupt, B. 2016. Close-range photogrammetry for 3-D ichnology: the basics of photogrammetric ichnology, p. 29-55. In Falkingham, P.L., Marty, D., and Richter, A. (eds.), Dinosaur Tracks: The Next Steps. Indiana University Press. Bloomington \& Indianapolis.

Nicosia, U., Marino, M., Mariotti, N., Muraro, C., Panigutti, S., Petti, F.M., and Sacchi, E. 2000a. The Late Cretaceous Dinosaurs tracksite near Altamura (Bari, Southern Italy) II Apulisauripus federicianus new ichnogen. and new ichnosp. Geologica Romana, 35(1999):237-247.

Nicosia, U., Marino, M., Mariotti, N., Muraro, C., Panigutti, S., Petti, F.M., and Sacchi, E. 2000b. The Late Cretaceous Dinosaurs tracksite near Altamura (Bari, Southern Italy) I - Geological framework. Geologica Romana, 35(1999):231-236.

Nikolakopoulos, K.G., Soura, K., Koukouvelas, I.K., and Agyropoulos, N.K. 2017. UAV vs classical aerial photogrammetry for archaeological studies. Journal of Archaeological Science: Reports, 14:758-773. https://doi.org/10.1016/j.jasrep.2016.09.004

Pajares, G. 2015. Overview and current status of remote sensing applications based on unmanned aerial vehicles (UAVs). Photogrammetric Engineering \& Remote Sensing, 81(4):281-329. http://doi.org/10.14358/PERS.81.4.281.

Petruzzelli, M. 2017. Studio stratigrafico-sedimentologico di alcuni intervalli di interesse regionale o globale nella successione albiano-cenomaniana della Piattaforma Carbonatica Apula. Unpublished PhD Thesis, Bari University, Italy.

Petruzzelli, M., Petti, F.M., Tropeano, M., Wagensommer, A., Francescangeli, R., La Perna, R., Sabato, L., and Spalluto, L. 2016. New ichnological and sedimentological data on the Molfetta dinosaur tracksite (early Albian, Apulia, Italy). In Ichnia 2016, Abstract Book.

Petti, F.M., Avanzini, M., Belvedere, M., De Gasperi M., Ferretti, P., Girardi, S., Remondino, F., and Tomasoni, R. 2008a. Digital 3D modelling of dinosaur footprints by photogrammetry and laser scanning techniques: integrated approach at the Coste dell'Anglone tracksite (Lower Jurassic, Southern Alps, Northern Italy). In Avanzini, M. and Petti, F.M. (eds.), Italian Ichnology, Proceedings of the Ichnology session of Geoitalia 2007. Studi Trentini di Scienze Naturali, Acta Geologica, 83:303-315.

Petti, F.M., D'Orazi Porchetti, S., Conti, M.A., Nicosia, U., Perugini, G., and Sacchi, E. 2008b. Theropod and sauropod footprints in the Early Cretaceous (Aptian) Laziale-AbruzzeseCampana Carbonate Platform (Esperia, Lazio, Central Italy): a further constraint on the palaeogeography of the Central-Mediterranean area. In Avanzini, M. and Petti, F.M. (eds.), Italian Ichnology, Proceedings of the Ichnology session of Geoitalia 2007. Studi Trentini di Scienze Naturali, Acta Geologica, 83:323-334.

Petti, F.M., D'Orazi Porchetti, S., Sacchi, E., and Nicosia, U. 2010. A new purported ankylosaur trackway in the Lower Cretaceous (lower Aptian) shallow-marine carbonate deposits of Puglia, southern Italy. Cretaceous Research, 31:546-552. https://doi.org/10.1016/ j.cretres.2010.07.004 
Pond, S., Lockley M.G., Lockwood J.A.F., Breithaupt, B.H., and Matthews, N.A. 2014. Tracking dinosaurs on the Isle of Wight: a review of tracks, sites, and current research. Biological Journal of the Linnean Society, 113:737-757. https://doi.org/10.1111/bij.12340.

Remondino, F., Alessandro, R., Stefano, G., Petti, F.M., and Avanzini, M. 2010. 3D ichnology recovering digital 3D models of dinosaur footprints. The Photogrammetric Record, 25:266282. https://doi.org/10.1111/j.1477-9730.2010.00587.x.

Romilio, A. and Salisbury, S.W. 2014. Large dinosaurian tracks from the Upper Cretaceous (Cenomanian-Turonian) portion of the Winton Formation, Lark Quarry, central-western Queensland, Australia: 3D photogrammetric analysis renders the 'stampede trigger' scenario unlikely. Cretaceous Research, 51:186-207. https://doi.org/10.1016/j.cretres.2014.06.003.

Romilio, A., Hacker, J.M., Zlot, R., Poropat, G., Bosse, M., and Salisbury, S.W. 2017. A multidisciplinary approach to digital mapping of dinosaurian tracksites in the Lower Cretaceous (Valanginian-Barremian) Broome Sandstone of the Dampier Peninsula, Western Australia. PeerJ, 5:e3013. https://doi.org/10.7717/peerj.3013

Sacchi, E., Conti, M.A., D’Orazi Porchetti, S., Logoluso, A., Nicosia, U., Perugini, G., and Petti, F.M. 2009. Aptian dinosaur footprints from the Apulian platform (Bisceglie, Southern Italy) in the framework of periadriatic ichnosites. Palaeogeography, Palaeoclimatology, Palaeoecology, 271:104-116. https://doi.org/10.1016/j.palaeo.2008.09.018

Salisbury, S.W., Romilio, A., Herne, M.C., Tucker, R.T., and Nair, J.P. 2017. The dinosaurian ichnofauna of the Lower Cretaceous (Valangian-Barremian) Broome Sandstone of the Walmadany area (James Price Point), Dampier Peninsula, Western Australia. Journal of Vertebrate Paleontology, 36(Supplement 1):1-152. https://doi.org/10.1080/ 02724634.2016.1269539.

Wings, O., Lallensack, J.N., and Mallison, H. 2016. The Early Cretaceous Dinosaur Trackways in Münchehagen (Lower Saxony, Germany)—3D photogrammetry as basis for geometric morphometric analysis of shape variation and evaluation of material loss during excavation, 56-70. In Falkingham, P.L., Marty, D., and Richter, A. (eds.), Dinosaur Tracks: The Next Steps. Indiana University Press. Bloomington \& Indianapolis.

Xing, L.-D., Lockley, M.G., Zhang, J., Klein, H., Marty, D., Peng, G., Ye, Y., McCrea, R.T., Persons, W.S., IV, and Xu, T. 2015. The longest theropod trackway from East Asia, and a diverse sauropod-, theropod-, and ornithopod-track assemblage from the Lower Cretaceous Jiaguan Formation, southwest China. Cretaceous Research, 56:345-362. https://doi.org/ 10.1016/j.cretres.2015.05.008. 
PETTI ET AL.: UAVS AND DINOSAUR TRACKSITES

\section{SUPPLEMENTAL MATERIAL}

Processing reports of the UAV aerial- and close-range photogrammetry. Available as a downloadable zipped file at palaeo-electronica.org/content/2018/2317-uavs-and-dinosaur-tracksites. 